\title{
Antioxidant Capacity Assessment of Two White Table Grape
}

\author{
Yanqiu Shen ${ }^{1, \#}$, Jiayu Zhao ${ }^{1, \#}$, Guihong Zhou ${ }^{3}$, Hui Xia ${ }^{2}$, Dong Liang ${ }^{2, a}$ \\ ${ }^{1}$ College of Horticulture, Sichuan Agricultural University, 611130 Chengdu, Sichuan, China \\ ${ }^{2}$ Institute of Pomology and Olericulture, Sichuan Agricultural University, 611130 Chengdu, Sichuan, China \\ ${ }^{3}$ Science-Technology \& Agriculture-Livestock Bureau of Wenchuan county, 623000 Aba Tibetan and Qiang Autonomous Prefecture, \\ Sichuan

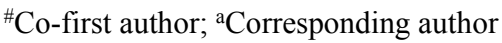

\begin{abstract}
Grapes can be an abundant source for polyphenols. This work was to extend the investigation to white grape antioxidants by determining antioxidants and antioxidant activity (DPPH, ABTS and FRAP). The results suggested the polyphenols of 'Italia' was significantly higher than 'Rosario Bianco'. But except FRAP, DPPH and ABTS were no difference between two withe cultivars. Moreover, the seeds of tested grape cultivars were the best source of antioxidants content and activity, followed by skins and then pulps of grapes.
\end{abstract}

\section{Introduction}

Table grape cultivation is very important in China, and Italia is the most important variety cultivated in the region. Both 'Italia' and 'Rosario Bianco' grape are Eurasian species. 'Italia' originated in Italy, and 'Rosario Bianco' native to Japan, both of which are the world famous table grape cultivars [1]. Due to the special with skin, the two cultivars were highly praised and appreciated by the consuming public. As we all known, grapes can be an abundant source for polyphenols, including the total phenolics content (TPC), total flavonoids content (TFC), total flavanols content (TFAC), total anthocyanins content (TMAC). The flavonoids account for a large parts of TPC, and are the most important non-anthocyanin in the grape fruit. It can be seen that the content of flavonoids directly affects the change trend of total non-anthocyanin [2]. A large number of studies have found that polyphenols in grape skin and grape seeds have obvious antioxidant activity, inhibit the proliferation of tumor cells and inhibit angiocardiopathy [3-5]. Research suggest that the phenolic and flavonoid contents in extracts of grape skins and pulps showed statistically significant correlations with the free radical scavenging activity[6]. Fruits are complex biological systems and contain a multiplicity of antioxidants. Therefore, there is no general single method, which can inspect accurately all antioxidants in fruits. Until now, several methods have been developed to evaluate the total antioxidant activity of different plants tissues. Among them, DPPH, ABTS and FRAP are the representative methods frequently used in various researches [7]. The antioxidant activity of different grapes detected by DPPH, ABTS or FRAP have been studied widely in the literature. DPPH and ABTS were used to investigate the antioxidant capacities among four grapes pomace extracts [8]. The purpose of this work was to extend the investigation to white grape antioxidants and the results will provide a theoretical basis for the quality identification of the two grapes.

\section{Materials ad methods}

\subsection{Plant material}

The two grape cultivars (Vitis vinifera L.) were collected on 2018, all of which planted in a commercial table grape vineyard located in the territory of Yong-an town $\left(\mathrm{N} 30^{\circ} 24^{\prime}, \mathrm{E} 103^{\circ} 59^{\prime}\right)$, Chengdu, China. Both the grape varieties were cultivated under the plastic rain shelter and the planting spacing was $3 \mathrm{~m} \times 1 \mathrm{~m}$. Field management (Fertilizer, pest control, and other vineyard operations) was performed according to local practices.

Grape samples of $2 \mathrm{~kg}$ for each variety were harvested manually at full mature stage. After that, grapes berry were brought to the laboratory immediately. Seeds, skins and pulps were carefully separated manually and stored at $-80^{\circ} \mathrm{C}$ for further determination.

\subsection{Method}

Seeds, skins and pulps extracts of different cultivars and tissues were determined the total phenolic content by the Folin-Ciocalteu method [9]. The method of Jia et al was conducted to determine the total flavonoids content of seeds, skins and pulps extracts [10]. The TFAC of seeds, skins and pulps extracts was detected with p-DMACA [11]. The TMAC of seed, skin and pulp extracts was estimated by the $\mathrm{pH}$ differential method [12]. The DPPH (2,2-diphenyl-1-picrylhydrazyl) scavenging activity was determined based on an assay modified by

\footnotetext{
a Corresponding author: 756141959@qq.com
} 
Brandwilliams et al. [13]. The ABTS (2,2-azino-bis (3ethylbenzothiazoline-6-sulfonic acid) diammonium salt) assay was based on the method from Re et al. [14]. The FRAP (ferric reducing antioxidant power) was measured by following a procedure derived from Benzie and Strains [15].

\subsection{Statistical analysis}

All index analysis was performed with three replicates. The mean and standard error of means were presented as the results. Data were analyzed by using SPSS 22.0 by one way analysis of variance (ANOVA). A multiple comparison procedure of the treatment means was performed by Duncan Test. Significance of the differences was defined as $P<0.05$.

\section{Results}

\subsection{Cultivars characteristics}

The two tested cultivars have white appearance, belong to late variety. Besides, both 'Italia' and 'Rosario Bianco' have detected seeds.

Table 1. Setting Word's margins

\begin{tabular}{ccc}
\hline Grape cultivar & Skin color & Seeds (Y/N) \\
\hline Italia & White & Y \\
Rosario Bianco & White & Y seeds.
\end{tabular}

\subsection{TPC of different tissues in two withe cultivars}

The total phenolics content of extracts measured by the Folin-Ciocalteu method was shown in Table 2. There were significant differences $(p<0.05)$ between 'Italia' and 'Rosario Bianco'. Moreover, the total content of phenolic compounds differed from different grape tissues. The TPC of skin in 'Italia' was 327.5 and in 'Rosario Bianco' is $295.0 \mathrm{mg}$ GAE/kg FW. The total phenolics content of 'Italia' was significantly higher than 'Rosario Bianco'. The TPC was 54.4 and $57.5 \mathrm{mg}$ GAE/kg FW in the pulp of 'Italia' and 'Rosario Bianco' respectively, meanwhile 4213.2 and $4010.9 \mathrm{mg} \mathrm{GAE} / \mathrm{kg}$ FW in the seeds 'Italia' and 'Rosario Bianco' respectively (Table 2). 'Italia' grape contained the highest contents of total phenolics in the skins and seeds, 'Rosario Bianco' in pulp. In comparison with TPC in different tissues, seeds had highest content, followed by skins, while TPC in pulps was absolutely less than that of skin and seeds.

Table 2. TPC of different tissues in two withe cultivars

\begin{tabular}{cccc}
\hline \multirow{2}{*}{$\begin{array}{c}\text { Grape } \\
\text { cultivar }\end{array}$} & \multicolumn{3}{c}{ TPC (mg GAE/kg FW) } \\
\cline { 2 - 4 } & Skin & Pulp & Seed \\
\hline Italia & $327.5 \pm 11.5 \mathrm{a}$ & $54.4 \pm 6.1 \mathrm{~b}$ & $4213.2 \pm 189 \mathrm{a}$
\end{tabular}

Rosario

Bianco

$295.0 \pm 17.8 \mathrm{~b} \quad 57.5 \pm 11.4 \mathrm{a}$

$4010.9 \pm 177 \mathrm{~b}$

GAE, gallic acid equivalent.

Values are means \pm SD values of three replicates.

Different letters indicate significant difference at $p<0.05$ by

Duncan's test.

\subsection{TFC of different tissues in two withe cultivars}

The total flavonoids content and total phenolics content differed significantly, while exhibiting the same rank order among grape cultivars extracts (Table 3). TFC of skin in 'Italia' was 631.7 and in 'Rosario Bianco' was $741.3 \mathrm{mg} \mathrm{GAE} / \mathrm{kg} \mathrm{FW}$. The total flavonoids content of 'Rosario Bianco' was significantly higher than 'Italia'. The TFC was 168.0 and $175.6 \mathrm{mg}$ GAE/kg FW in the pulp of 'Italia' and 'Rosario Bianco' respectively, meanwhile 10645.5 and $10525.2 \mathrm{mg} \mathrm{GAE} / \mathrm{kg} \mathrm{FW}$ in the seeds 'Italia' and 'Rosario Bianco' respectively. Among all cultivars, seeds had the highest TFC, followed by those from skins and pulps.

Table 3. TFC of different tissues in two withe cultivars

\begin{tabular}{cccc}
\hline Grape & \multicolumn{3}{c}{ TFC (mg RE/kg FW) } \\
\cline { 2 - 4 } cultivar & Skin & Pulp & Seed \\
\hline Italia & $631.7 \pm 47.8 \mathrm{~b}$ & $168.0 \pm 13.7 \mathrm{~b}$ & $10645.5 \pm 182.3 \mathrm{a}$ \\
Rosario & $741.3 \pm 38.2 \mathrm{a}$ & $175.6 \pm 12.5 \mathrm{a}$ & $10525.2 \pm 177.2 \mathrm{~b}$ \\
Bianco & & & \\
RE, gallic acid equivalent. & \\
Values are means \pm SD values of three replicates. \\
Different letters indicate significant difference at $p<0.05$ by \\
Duncan's test.
\end{tabular}

\subsection{TFAC of different tissues in two withe cultivars}

Total flavanols content of seeds, skins and pulps extracts measured by p-DMACA was shown in Table 4 . The TPC of skin in 'Italia' was 100.9 and in 'Rosario Bianco' was $140.1 \mathrm{mg} \mathrm{GAE} / \mathrm{kg}$ FW. The total flavanols content of 'Rosario Bianco' was significantly higher than 'Italia'. The TFAC was 12 and $9.4 \mathrm{mg} \mathrm{GAE} / \mathrm{kg} \mathrm{FW}$ in the pulp of 'Italia' and 'Rosario Bianco' respectively, meanwhile 2000.7 and $1610.7 \mathrm{mg} \mathrm{GAE} / \mathrm{kg} \mathrm{FW}$ in the seeds 'Italia' and 'Rosario Bianco' respectively (Table4). 'Italia' grape contained the highest contents of TFAC in the pulp and seeds, 'Rosario Bianco' in skin.

Table 4. TFAC of different tissues in two withe cultivars

\begin{tabular}{cccc}
\hline Grape & \multicolumn{3}{c}{ TFAC (mg CE/kg FW) } \\
\cline { 2 - 4 } cultivar & Skin & Pulp & Seed \\
\hline Italia & $100.9 \pm 5.3 \mathrm{~b}$ & $12 \pm 2.3 \mathrm{a}$ & $2000.7 \pm 120.5 \mathrm{a}$ \\
$\begin{array}{c}\text { Rosario } \\
\text { Bianco }\end{array}$ & $140.1 \pm 12.0 \mathrm{a}$ & $9.4 \pm 0.2 \mathrm{~b}$ & $1610.7 \pm 80.5 \mathrm{~b}$ \\
\hline
\end{tabular}

CE, catechin equivalent.

Values are means \pm SD values of three replicates.

Different letters indicate significant difference at $p<0.05$ by Duncan's test. 


\subsection{TMAC of different tissues in two withe cultivars}

Due to the withe peel of two cultivars, the total anthocyanins content in different tissues was low. The TMAC of skin in 'Italia' was 18.1 and in 'Rosario Bianco' was $28.9 \mathrm{mg}$ GAE $/ \mathrm{kg}$ FW. The total anthocyanins content of 'Rosario Bianco' was significantly higher than 'Italia'. The TFAC was 0.3 and $1.4 \mathrm{mg} \mathrm{GAE} / \mathrm{kg} \mathrm{FW}$ in the pulp of 'Italia' and 'Rosario Bianco' respectively. Moreover, TMAC of seeds in two cultivars were not detected because seeds may not contain anthocyanins.

Table 5. TMAC of different tissues in two withe cultivars

\begin{tabular}{cccc}
\hline Grape & \multicolumn{3}{c}{ TMAC $(\mathrm{mg}$ C3GE $/ \mathrm{kg} \mathrm{FW})$} \\
\cline { 2 - 4 } cultivar & Skin & Pulp & Seed \\
\hline Italia & $18.1 \pm 2.5 \mathrm{~b}$ & $0.3 \pm 0.1 \mathrm{~b}$ & NA \\
$\begin{array}{c}\text { Rosario } \\
\text { Bianco }\end{array}$ & $28.9 \pm 2.6 \mathrm{a}$ & $1.4 \pm 0.3 \mathrm{a}$ & NA \\
\hline
\end{tabular}

NA, not available; and C3GE, cyanidin 3-glucoside equivalent. Values are means $\pm \mathrm{SD}$ values of three replicates.

Different letters indicate significant difference at $p<0.05$ by

Duncan's test.

\subsection{Antioxidant capacity of different tissues in two withe cultivars}

The DPPH, ABTS and FRAP values of skins, pulps and seeds fractions of 4 table grapes were presented in Table 6,7 and 8 on the basis of $\mu$ mol Trolox equivalent (TE)/g FW.

In the skin, two cultivars of Trolox equal antioxidant capacity values measured by DPPH were 22.4 and 21.4; ABTS were 38.4 and 38.1 ; and by FRAP, 419.8 and 409.7. In the seeds, antioxidant activity of DPPH, ABTS and FRAP were 108.5 and 109.1, 189.8 and 184.7, and 3266.1 and 3118.6, respectively. However, the DPPH, ABTS and FRAP values of pulp were 16.5 and 16.6, 13.1 and 12.6, and 185.6 and 189.1.

In parallel to the antioxidant activity data of 2 withe skin grape cultivars determined by DPPH, ABTS and FRAP assay, seeds were the highest in antioxidant activity followed by skins. Pulp of grape showed the lowest antioxidant activity (Table 6, 7,8). Above all, the capacity of 'Italia' was higher than 'Rosario Bianco' and the seeds of tested grape cultivars were the best source of antioxidants content and activity, followed by skins and then pulps of grapes.

Table 6. DPPH of different tissues in two withe cultivars

\begin{tabular}{cccc}
\hline Grape & \multicolumn{3}{c}{ DPPH $(\mu \mathrm{mol}$ TE/g FW $)$} \\
\cline { 2 - 4 } cultivar & Skin & Pulp & Seed \\
\hline Italia & $22.4 \pm 0.8 \mathrm{fa}$ & $16.5 \pm 1.9 \mathrm{a}$ & $108.5 \pm 2.8 \mathrm{a}$ \\
$\begin{array}{c}\text { Rosario } \\
\text { Bianco }\end{array}$ & $21.4 \pm 0.8 \mathrm{~b}$ & $16.6 \pm 1.5 \mathrm{a}$ & $109.1 \pm 3.0 \mathrm{a}$ \\
\hline
\end{tabular}

TE, trolox equivalent.

Values are means \pm SD values of three replicates.

Different letters indicate significant difference at $p<0.05$ by

Duncan's test.
Table 7. ABTS of different tissues in two withe cultivars

\begin{tabular}{cccc}
\hline \multirow{2}{*}{ Grape cultivar } & \multicolumn{3}{c}{ ABTS $(\mu \mathrm{mol} \mathrm{TE} / \mathrm{g} \mathrm{FW})$} \\
\cline { 2 - 4 } & Skin & Skin & Skin \\
\hline Italia & $38.4 \pm 2.0 \mathrm{a}$ & $13.1 \pm 0.6 \mathrm{a}$ & $189.8 \pm 14.0 \mathrm{a}$ \\
$\begin{array}{c}\text { Rosario } \\
\text { Bianco }\end{array}$ & $38.1 \pm 2.6 \mathrm{a}$ & $12.6 \pm 1.0 \mathrm{~b}$ & $184.7 \pm 9.0 \mathrm{~b}$ \\
\hline
\end{tabular}

TE, trolox equivalent.

Values are means \pm SD values of three replicates.

Different letters indicate significant difference at $p<0.05$ by

Duncan's test.

Table 8. FRAP of different tissues in two withe cultivars

\begin{tabular}{cccc}
\hline \multirow{2}{*}{ Grape cultivar } & \multicolumn{3}{c}{ FRAP $(\mu \mathrm{mol} \mathrm{TE} / \mathrm{g} \mathrm{FW})$} \\
\cline { 2 - 4 } & Skin & Skin & Skin \\
\hline Italia & $419.8 \pm 43.1 \mathrm{a}$ & $185.6 \pm 11.7 \mathrm{~b}$ & $3266.1 \pm 270.8 \mathrm{a}$ \\
$\begin{array}{c}\text { Rosario } \\
\text { Bianco }\end{array}$ & $409.7 \pm 24.7 \mathrm{~b}$ & $189.1 \pm 8.7 \mathrm{a}$ & $3118.6 \pm 316.2 \mathrm{~b}$ \\
\hline
\end{tabular}

TE, trolox equivalent.

Values are means \pm SD values of three replicates.

Different letters indicate significant difference at $p<0.05$ by

Duncan's test.

\section{Discussion}

Phenolic compounds and Phenolic wine by-products, such as wine have attracted much interest due to their antioxidant and antimicrobial properties and their potentially beneficial effects for human health $[16,17]$. Many workers have reported the importance of phenolic compounds as protector of human health in different ways [3-5]. Our study showed 'Italia' grape contained the highest contents of total phenolics in the skins and seeds, but 'Rosario Bianco' in pulp, and the polyphenols differed from different tissues, while there was no significantly difference detected in the antioxidant activity (DPPH and ABT).

\section{Conclusion}

In all, the polyphenols of 'Italia' was significantly higher than 'Rosario Bianco'.But except FRAP, DPPH and ABTS were no difference between two withe cultivars. Moreover, the seeds of tested grape cultivars were the best source of antioxidants content and activity, followed by skins and then pulps of grapes.

\section{References}

1. Q.S. Kong. China Grapes. (China's Agricultural Science and Technology Press, 2004).

2. S.M. Jiang, Z.M. Jin, N.N. Liang, H.Q. Bi, C.Q. Duan. Changes of non-anthocyanin phenolic compounds in Syrah grape skin during ripening. Sino-Overseas Grapevine \& Wine,13 : 20-24(2008).

3. J.H. Lee, J.V. Johnson, S.T. Talcott. Identification of ellagicconjugates and other polyphenolics in muscadine grapes by HPLC-ESI-MS. J Agric Food Chem 53:6003-6010(2005). 
4. AE Banini, L.C. Boyd, J.C. Allen, H.G. Allen, D.L. Sauls. Muscadine grape products intake, diet and blood constituents of non-diabetic and type 2 diabetic subjects. Nutrition 22:1137-1145(2006).

5. D. Del Pozo-Insfran, D. Del Follo-Martinaz, S.T. Talcott, C.H. Brenes. Stability of co-pigmented anthocyanins and ascorbic acid in muscadine grape juice processed by high hydrostatic pressure.J Food Sci 72:247-253(2007).

6. S.H. Nile, S.H. Kim, E.Y. Ko, S.W. Park. Polyphenolic Contents and Antioxidant Properties of Different Grape (V. vinifera, V. labrusca, and V. hybrid) Cultivars. BioMed Res. Int., 5 (2013).

7. J.F. Meng, Y.L. Fang, M.Y. Qin, X.F. Zhuang, Z.W. Zhang. Varietal differences among the phenolic profiles and antioxidant properties of four cultivars of spine grape (Vitis davidii Foex) in Chongyi County (China). Food Chem 134:2049-2056(2012).

8. Y.X. Xu, S. Burton, C. Kim, E. Sismour. Phenolic compounds, antioxidant, and antibacterial properties of pomace extracts from four Virginia-grown grape varieties. Food Sci Nutr 4(1):125-133 (2016).

9. V.L. Singleton, J.A. Rossi. Colorimetry of total phenols with phosphomolybdic phosphotungstic acid reagents. Am J Enol Vitic 16: 144-158(1965).

10. Z.S. Jia, M.C. Tang, J.M. Wu. The determination of flavonoid contents in mulberry and their scavenging effects on superoxide radicals. Food Chem 64(4): 555-559(1999).

11. Y.G. Li, G. Tanner, P. Larkin The DMACA-HCl protocol and the threshold proanthocyanidin content for bloat safety in forage legumes. J Sci Food Agric 70(1): 89-101(1996).

12. X.Q. Wang, C.Y. Li, D. Liang, Y.J. Zou, P.M. Li, F. Ma. Phenolic compounds and antioxidant activity in red-fleshed apples. J Funct Foods 18: 10861094(2015).

13. W. Brandwilliams, M.E. Cuvelier, M.E. Berset. Use of a free-radical method to evaluate antioxidant activity. Food Sci Technol 28(1):25-30 (1995).

14. R. Re, N. Pellegrini, A. Proteggente, A. Pannala, M. Yang, C. Rice-Evans. Antioxidant activity applying an improved ABTS radical cation decolorization assay. Free Radical Bio Med 26(9-10): 12311237(1999).

15. I.F.F. Benzie, J.J .Strain. The ferric reducing ability of plasma (FRAP) as a measure of "antioxidant power": The FRAP assay. Anal Biochem 239(1): 70-76(1996).

16. J. Sun, Y.F. Chu, X. Wu, R.H. Liu. Antioxidant and antiproliferative activities of common fruits. J Agric Food Chem 50:7449-7454(2002).

17. N.G. Baydar, O. Sagde, G. Ozkan, E.S. $\mathrm{C}$, etin.Determination of antibacterial effects and total phenolic contents of grape (Vitis vinifera L.) seed extracts. Int J Food Sci Technol 41:799804(2006). 